\title{
Characterization And Cytotoxicity of Novel Synthesis Selenium Nanoparticles Stabilized By Vitamin E TPGS.
}

\author{
*Haider Hamzah Al-Shreefy ${ }^{1}$ Mohammed J Al-Awady ${ }^{2}$, Estabraq Al-Wasiti ${ }^{3}$, \\ ${ }^{(1)}$ Department of Biochemistry, College of Medicine, Nahrain University, Baghdad, Iraq. \\ ${ }^{(2)}$ Department of Genetic Engineering, College of Biotechnology. Al Qasim Green University \\ ${ }^{(3)}$ Department of Biochemistry, College of Medicine, Nahrain University, Baghdad, Iraq. \\ Correspond author email:haiderhamzabed@gmail.com
}

Mobile :00964-7725503941

\begin{abstract}
:
The aim of this research was to investigate synergistic effect of combination two related antioxidant agents by novel synthesis of selenium nanoparticles functionalized with D- $\alpha$ Tocopherol polyethylene glycol 1000 succinate (TPGS) as a capping agent during chemical reduction of sodium selenite by ascorbic acid. Particle size, morphology, crystallite size of synthesized Se-TPGS were characterized by dynamic light scattering (DLS), transmission electron microscopy (TEM), Field Emission Scanning Electron Microscopy (FESEM), Ultraviolet-Visible spectrophotometry (UV/Vis), X-Ray diffraction (XRD). The in vitro antioxidant activity, cell toxicity and blood compatibility assays were investigate respectively. The DLS results revealed that the Se-TPGS possess very low polydispersity index value (PDI = 0.03 ) and having hydrodynamic particle size of $83.33 \pm 14.7 \mathrm{~nm}$ with negatively value for zeta potential equal to $-19.5 \mathrm{mV}$. Both SEM and TEM show regular spherical shape of SeNPs with size measurement less than DLS measuring. XRD result confirming that the produced SeNPs possessed a standard crystalline hexagonal phase structure. DPPH assay of total antioxidant activity display high antioxidant activity of Se-TPGS NPs when comparing with ascorbic acid as a reference material. The cytotoxicity of new formula Se-TPGS investigated for both cancerous (MCF-7) and normal (HBL-100) breast cell lines with significantly different. This study provides a facile and green method for chemically synthesizing stable SeNPs which are suitable for further evaluation in therapeutic applications. The SeNPs could be a blueprint in the field of biomedical application as an alternative chemotherapy for fighting cancerous cells.
\end{abstract}


Keywords: Selenium nanoparticles, TPGS, anticancer drugs.

\section{Introduction:}

The high number of new cancer rates and the related mortality continue to be worrying, leading to the investigate for new therapies that would be more effective and less burdensome for patients. As there is evidence that Se compounds can have anticancer and preventive activity, studies have begun to establish whether these compounds can also affect already existing cancers [1]. Selenium (Se) is a metalloid and essential trace element has crucial role for human as an active moiety related to 25 Se-containing proteins [2]. Most of them having a biological redox activities except one called Selenoprotein $\mathrm{P}$ act primarily as a transporter for Se [3]. The normal plasma concentration of Se is about $106 \mathrm{ng} / \mathrm{ml}$ to $121 \mathrm{ng} / \mathrm{ml}$ exhibited a preventing and protecting effect against many types of cancers in experimental studies [4]. In the human body Se, has several biological functions and roles such as strong antioxidant action [5]. Se has a number of immune functions including proliferation and activity of lymphocytes (Natural killer and T- cells) [6]. Normal plasma Se concentrations decrease cardiovascular diseases risk [7]. Se doesn't exert its antioxidant activity alone but work together with vitamin $\mathrm{E}$ in preventing lipids peroxidation by scavenging free radicals [5]. In addition to their anticancer potential the SeNPs have others medical application such as antibacterial, antiviral, antioxidant and antidiabetic applications [8].

\section{Materials and methods}

\section{Materials}

Trypsin/EDTA, Roswell Park Memorial Institute (RPMI-1640) media and Fetal bovine serum (FBS) purchased from Capricorn. L-Ascorbic acid were purchased from Alpha Chemika. Sodium selenite was purchased from HIMEDIA. Tocopherol Polyethylene Glycol 1000 Succinate (TPGS) was purchased from Antares. (MTT) purchased from Bio-World and dimethyl sulfoxide (DMSO) were purchased from 
Santacruz Biotechnology, penicillin streptomycin were purchased from Invitrogen. DPPH purchased from (Sigma-Aldrich, USA).

\section{Methods}

\section{Selenium Nanoparticles synthesis}

Stock solution of sodium selenite $40 \mathrm{mM}$ were prepared by dissolving $346 \mathrm{mg}$ in $50 \mathrm{ml} \mathrm{D.} \mathrm{H}_{2} \mathrm{O}$, then by dilution prepared $1 \mathrm{mM}$ and 5 solutions. Ascorbic acid (AA) as a reducing agent for synthesis of SeNPs the solution of $0.3 \mathrm{M}$ was freshly prepared by dissolving $1.32 \mathrm{~g}$ of AA crystals in $25 \mathrm{~mL}$ of D. $\mathrm{H}_{2} \mathrm{O}$. The ascorbic acid solution oxidized and converted to dehydroascorbic acid (DHA) when exposed to air or light so must be prepare freshly [9]. $0.01 \mathrm{~g}$ of TPGS was dissolved in 500 $\mathrm{ml}$ D. $\mathrm{H}_{2} \mathrm{O}$. Mixing of $5 \mathrm{~mL}$ sodium selenite solution with $5 \mathrm{~mL}$ TPGS solution under magnetic mixing at the speed of $600 \mathrm{rpm}$ then $5 \mathrm{ml}$ of ascorbic acid added drop wise with stirring reduced to half speed, then $10 \mathrm{ml}$ of $\mathrm{D} . \mathrm{H}_{2} \mathrm{O}$ added to complete final volume $25 \mathrm{ml}$. The solution converted gradually from colorless into intense orange-red gradually, the reaction was allowed for a total of 24 hour to ensure high yield of SeNPs with homogeneous nano-size, all aforementioned done at room temperature.

\section{Purification of Selenium Nanoparticles (SeNPs)}

Se-TPGS NPs can be purified by using dialysis bag with 12000 molecular weight cutoff for one hour, to remove the excess of TPGS and ascorbic acid, against 0.1 M phosphate buffer $\mathrm{pH}$ 7.4.

\section{Characterization}

\section{DLS and Zeta potential analysis}

The hydrodynamic size of selenium nanoparticles, size distribution and zeta potentional were determined by Non-Invasive Back Scatter (NIBS) Dynamic Light Scattering analyzer. 


\section{UV-Vis spectroscopy analysis}

The UV-Vis analysis was determined with scanning mode for the prepared SeTPGS NPs by using the UV/Vis spectrophotometer (UV/Vis Spectrophotometer, SHMADZU, Japan) which ranges from 200 to $800 \mathrm{~nm}$.

\section{Field Emission Scanning Electron Microscopy (FESEM)}

The surface morphology of synthesized Se-TPGS NPs were analyzed by using FESEM (using the JEOL JSM-7500F model, Japan) with an acceleration voltage of $5 \mathrm{kV}$.

\section{Transmission electron microscopy (TEM)}

$20 \mu \mathrm{L}$ of colloidal SeNPs were dropped onto 400 mesh carbon support film (copper mesh), for obtaining the images of the Se-TPGS nanoparticles TEM grids were used for the sample analysis on a transmission electron microscope (JEOL-JEM-2100 F, Japan) with an accelerating voltage of $80 \mathrm{Kv}$.

\section{X-Ray diffraction (XRD) Measurements:}

The sample of XRD was prepared that $25 \mathrm{~mL}$ Se-TPGS NPs were dried by using glass petri dish under the condition of $60{ }^{\circ} \mathrm{C}, 2$ days Figure (1) and used XRD instrument (XRD D8 DISCOVER, Bruker, USA) was carried out to study the crystallinity. The average crystallite size for all assigned peaks of the synthesized SeNPs was obtained at about $\mathrm{nm}$ by using the Debye Scherrer equation.

$\mathrm{D}=\mathrm{k} \lambda / \beta \operatorname{Cos} \theta$

Where, $\mathrm{D}$ being the average crystallite size in $\mathrm{nm}$.

$\mathrm{k}$ is a Scherrer constant (equal to 0.9 for spherical shape NPs).

Theta $(\theta)$ is the peak position (radians).

Represent the angle between incident beam and the scattering planes.

Lambda $(\lambda)$ is the used $X$ - ray wavelength $(0.15406 \mathrm{~nm})$. 
Beta $(\beta)$ the broadening full width at half maximum (FWHM) (radians).

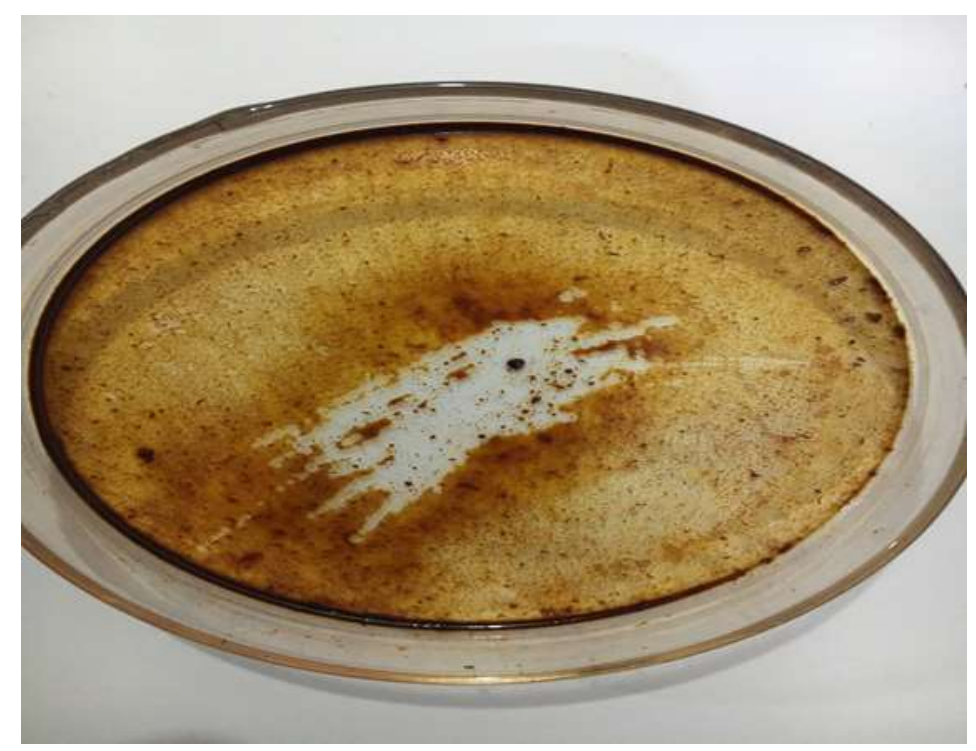

Figure (1) Dehydrated of Synthesized Se-TPGS NPs powder by using ascorbic reduction method.

\section{Acridine Orange -Ethidium Bromide Staining Principle}

Dissolve $15 \mathrm{mg}$ of acridine orange and $50 \mathrm{mg}$ ethidium bromide in $1 \mathrm{ml}$ of ethanol, then complete to $50 \mathrm{ml}$ distilled water with mixing, this stock solution divided into 1 $\mathrm{ml}$ aliquot and kept freeze in $-20{ }^{\circ} \mathrm{C}$ for three months, to prepare working solution of $\mathrm{AO} / \mathrm{EtBr}$ dual staining thawing of $1.0 \mathrm{ml}$ aliquot in $100 \mathrm{ml}$ Hanks' Balanced Salt Solution (HBSS) stable for one month [10]. Culture the MCF-7 cells at $2.0 \times 10^{6}$ cells/mL and incubate for 24 hours with tested SeNPs. Harvest the MCF-7 cells by trypsinization then centrifugation to collect cell pellet then washing the MCF-7 cells for two times and re-suspended in cold phosphate buffered saline. Staining with 100 $\mu \mathrm{L}$ of $\mathrm{AO} / \mathrm{EB}$ solution then mix smoothly for 2 minutes before visualized by fluorescence microscope and directly assess the sample [11].

\section{In vitro Antioxidant activity by DPPH}


The scavenging capacity of the Se-TPGS was evaluated using a stable DPPH assay. A total of $500 \mu \mathrm{L}$ of the Se-TPGS was added to $500 \mu \mathrm{L}$ of DPPH, and the volume was made up to $2 \mathrm{~mL}$ using absolute ethanol. The absorbance of each compound was measured at $517 \mathrm{~nm}[12]$. The free radical scavenging test (DPPH), was achieved in triplicates measurement and the results were presented as the mean \pm SD. DPPH radical scavenging activity of SeNPs was calculated by the following formula :

DPPH Scavenging Activity $(\%)=\frac{(A c-A s)}{A c} \times 100$

Where, $A c=$ Absorbance of the control at $517 \mathrm{~nm}$ and As $=$ Absorbance of samples or tested compounds at $517 \mathrm{~nm}$.

\section{In Vitro Cytotoxicity Assay}

Cancerous (MCF-7) and non-cancerous (HBL-100) breast cell lines were used for evaluating the cytotoxicity of Se-TPGS NPs, both types of cell were maintained in RPMI-1640 media supplemented with 10\% fetal bovine serum (FBS), and a mixture of penicillin $(100 \mathrm{U} / \mathrm{mL})$ and streptomycin $(100 \mu \mathrm{g} / \mathrm{mL})$ to avoid microbial contamination. Cells were passaged using Trypsin-EDTA reseeded at $80 \%$ confluence twice a week, and incubated humidified atmosphere incubator (Cypress Diagnostics, Belgium) of $5 \% \mathrm{CO}_{2}$ at $37{ }^{\circ} \mathrm{C}$ [13] and [14]. Cell viability were measured to compare the in vitro cytotoxicity of Se-TPGS. MCF-7 and HBL-100 Both cell lines were seeded at $1 \times 10^{4}$ cells/well into 96-well plates. After 24 hours or a confluent monolayer was achieved, cells were treated with tested compound at different concentration. RPMI-1640 media without any treatment was used as a control. Cell viability was measured after 72 hours of treatment by removing the medium, adding $28 \mu \mathrm{L}$ of $2 \mathrm{mg} / \mathrm{mL}$ solution of MTT and incubating the cells for 2.5 hours at $37{ }^{\circ} \mathrm{C}$. After removing the MTT solution, the crystals remaining in the wells were solubilized by the addition of $130 \mu \mathrm{L}$ of DMSO (Dimethyl Sulphoxide) 
followed by $37{ }^{\circ} \mathrm{C}$ incubation for 15 minutes with shaking [15]. The absorbency was determined on a microplate reader (Microtiter reader, Gennex Lab, USA) at $492 \mathrm{~nm}$; the assay was performed in triplicate. The inhibition rate of cell growth (the percentage of cytotoxicity) was calculated as the following equation [16].

Cytotoxicity $=\mathrm{A}-\mathrm{B} / \mathrm{A} * 100$

Where A and B are the optical density of control and the of test respectively.

\section{Hemolytic activity on red blood cells}

Blood samples were obtained from healthy volunteers. The tested nanomaterials were added to blood samples at concentration of $10 \mu \mathrm{g} / \mathrm{mL}$. After $60 \min$ of incubation at $37 \mathrm{C}$. Fluorescent intensity of RBCs was examined using fluorescent microscope [17].

\section{Results and discussion}

\section{Synthesis of SeNPs-TPGS}

The chemical reduction of selenium ion $\left(\mathrm{Se}^{+4}\right)$ with ascorbic acid in aqueous solution was formulated in Figure (2). Mees and coworkers were first introduced the development of dispersal colloidal solution of selenium by using ascorbic acid as the reducing agent [18]. This study agreed with Mees, the colloidal system was unstable without surface functionalization and leading to settled brick-red precipitate was clearly observed after a few minutes of reaction. The color of the precipitate transformed into biologically inert grey-black selenium form after two days, indicating that the structure of elemental selenium rearranged from monoclinic state particles into trigonal selenium [19].

On the other side, the SeNPs colloidal solution in the presence of TPGS as stabilizer showed an orange-red color, which return to a nano-size outcome. The 
uniform Se-TPGS NPs were synthesized after a few minutes of adding ascorbic acid to reaction mixture (sodium selenite and TPGS) with magnetic stirring. The time of mixing has been extended for 24 hours to ensure high conversation rate of selenite to SeNPs with homogeneous nano-sized particle size. The time required for reduction $\mathrm{Se}$ precursor $\left(\mathrm{Na}_{2} \mathrm{SeO}_{3}\right)$ to creates SeNPs was a few seconds by applying this chemical method compare to Mishra biological method that require 40 hours for complete reduction process for same precursor [20]. The chemical reduction methods, particularly that utilize not hazardous materials, are generally used to yield uniform and sized control nanoparticles [21]. Finally the nanoparticles are synthesized by this method is low costing, efficient energy use, non-hazardous and environment friendly.

The improvement of a simple, effectual as well as greener strategy for the synthesis and stabilize of SeNPs (with less than $100 \mathrm{~nm}$ size) has attracted growing interest, because biomolecules, especially vitamins, have been used in recent times for the synthesis and functionalization of well-dispersed SeNPs in aqueous medium [22]. SeNPs (naked or functionalized) and vitamin $\mathrm{E}$ have been investigated individually in cancer treatment researches [23], [24] and [25]. In other hand investigate potential advantage of both SeNPs and vitamin E effect in two formulas for different aspects [26] and [27]. Only this study assembling these two materials in one formula by using one of eight forms of a vitamin $\mathrm{E}$ as a stabilizing agent. Synthesis of SeNPs particle confirmed by DLS measurement Figure (3). The particle size of SeNPs-TPGS was $83.33 \pm 14.7 \mathrm{~nm}$ based on DLS measurements of size distribution with very small polydispersity index (PDI $=0.03)$. TPGS played an crucial role in capping and stabilizing the SeNPs. Because of the nanosize of the selenium particles and interference of ascorbic acid in the redox system. 


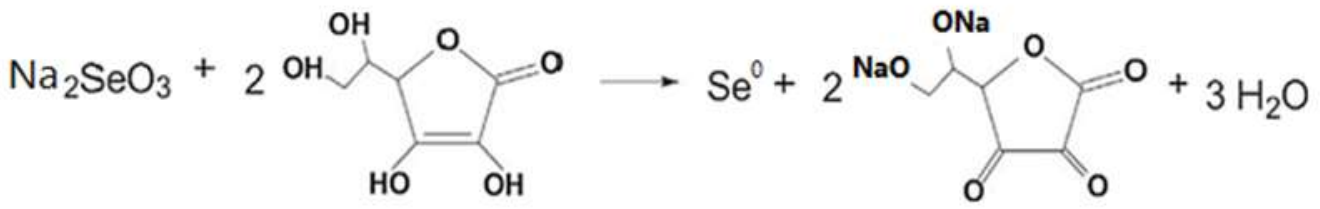

Figure (2) Chemical reaction of sodium selenite with ascorbic acid in aqueous solution to produce SeNPs.

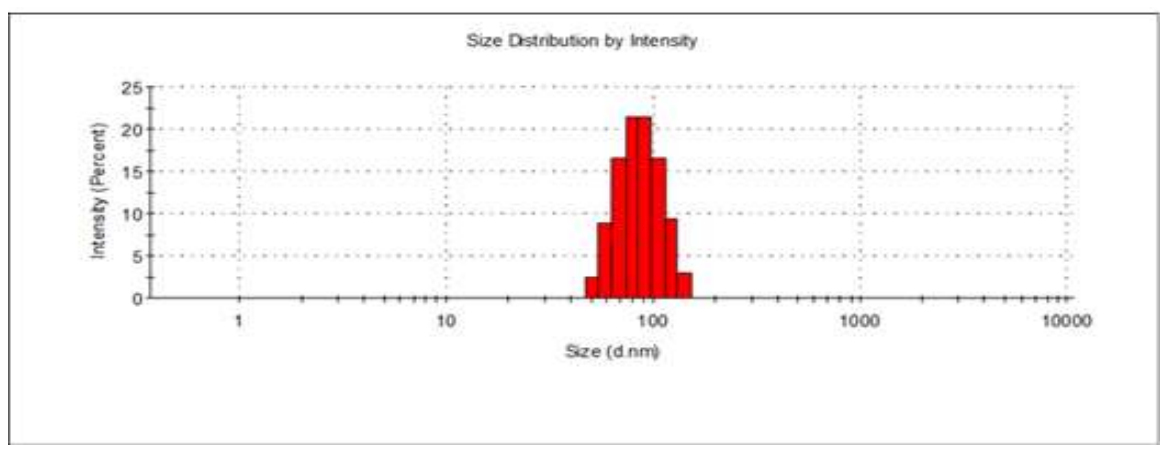

Figure (3) Size distribution of synthesized SeNPs.

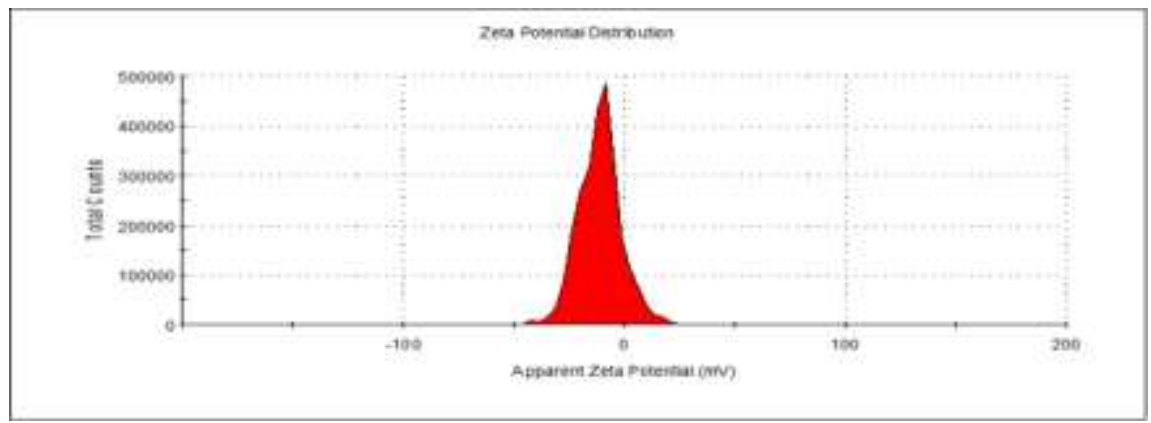

Figure (4) Zeta potential measurement for synthesized Se-TPGS NPs.

\section{UV-Vis spectrometry}

Chemical synthesis of SeNPs from $5 \mathrm{mM}$ sodium selenite was confirmed by UVVis spectrum study, due to change in selenite solution colorless to brick-red color SeNPs colloidal solution that exhibited single and strong absorption peak at $\lambda_{\max }=$ 
$261 \mathrm{~nm}$ Figure (5) when scanned by UV-Vis spectrophotometer between $(200 \mathrm{~nm}$ to $800 \mathrm{~nm}$ ). The vivid and colorful appearance of prepared colloidal SeNPs return to surface plasmon resonances (SPRs) that exhibited by metal nanoparticles when converted from ionic state (in selenite case $\mathrm{Se}^{+4}$ ) to elemental state $\left(\mathrm{Se}^{0}\right)$, these extra electrons in the selenium atoms oscillate as a free electrons known as plasmon.

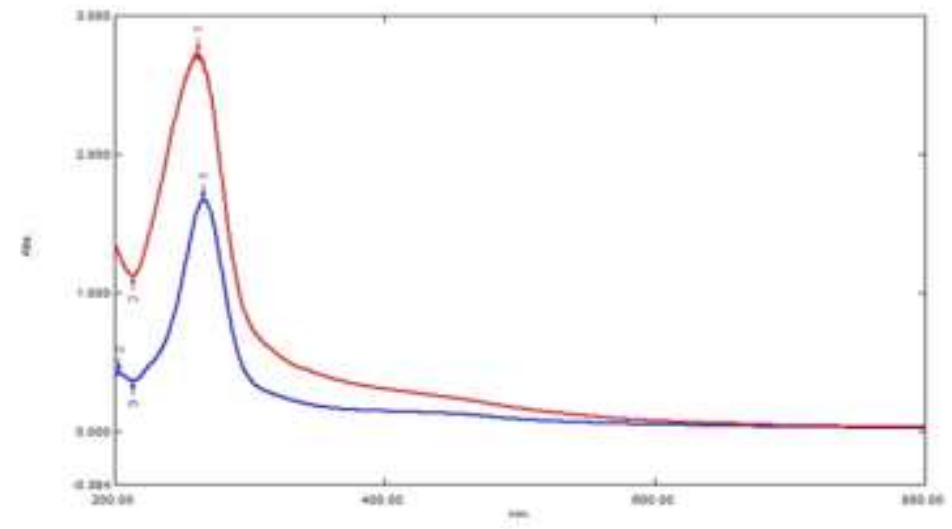

Figure 5 UV-Vis spectrum of Se-NPs $\lambda$ max $261 \mathrm{~nm}$.

The width of UV-Visible peak known as full width at half maximum (FWHM) is valuable tool that reflect a function of SeNPs plasmonic band and used as indicator for dispersity status (monodispersity or polydispersity). Monodispersity produces narrower absorbance bands while polydispersity offers broader ones [28]. Low FWHM shows amount of uniformity in the shape and size for prepared NPs (monodispersity). The ultraviolet SeNPs spectra between (260-265) $\mathrm{nm}$ that relates to the wavelength of the surface plasmon resonance of SeNPs and obtained not only for chemical reduction methods but also recorded for SeNPs synthesized with biological approaches was followed the such as reported outcome published by [29] and [30]. Khiralla study shows the peak was appeared at 
around $263 \mathrm{~nm}$ [31]. This peak appear at $262 \mathrm{~nm}$ when poly (sodium 4-styrene sulfonate) used as a stabilizer [32]. Countless reports confirm that the resonance peak of SeNPs absorbed light nearby this region, but the exact position peak width depends on numerous factors such as method of synthesis, reductant used, capping agent composition, size of NPs, shape of NPs and solution medium [33] and [32].

\section{X-Ray diffraction}

X-ray diffraction (XRD) analysis was used to assess the crystalline nature of synthesized SeNPs functionalized with TPGS, Figure (6) show the XRD data of produced SeNPs with four peaks of produced SeNPs. Both dried SeNPs had a 2theta degree of 10 to 80 , sharp strong peaks were detected at $23^{\circ}, 29^{\circ}, 41^{\circ}$, and $65^{\circ}$ for SeNPs, which corresponded to the Braggs planes (100), (101), (210), and (310), respectively, according to COD 9008579.

The XRD analysis confirming that the produced SeNPs possessed a hexagonal phase structure (more stable form at room temperature), It's worth noting that the broadening of the XRD peaks indicates that the grain sizes of the produced powder are on the nano scale. The Scherer formula equation applied to calculate the average crystalline size for all assigned peaks of the synthesized SeNPs was obtained equal to $5.08 \mathrm{~nm}$ [34]. The contrasting of this result appear in XRD spectrum of the SeNPs prepared by bio-reduction of sodium selenate $\left(\mathrm{Na}_{2} \mathrm{SeO}_{4}\right)$ exhibited a broad peak at a 2theta angle of 15-35 degree indicating amorphous nature of selenium crystal this return stabilizer effect [35]. Synthesized SeNps stabilized with bovine serum albumin offers single broad peak that revealed amorphous form of selenium because the stabilizer has high molecular weight 66 kilo Dalton [36]. 


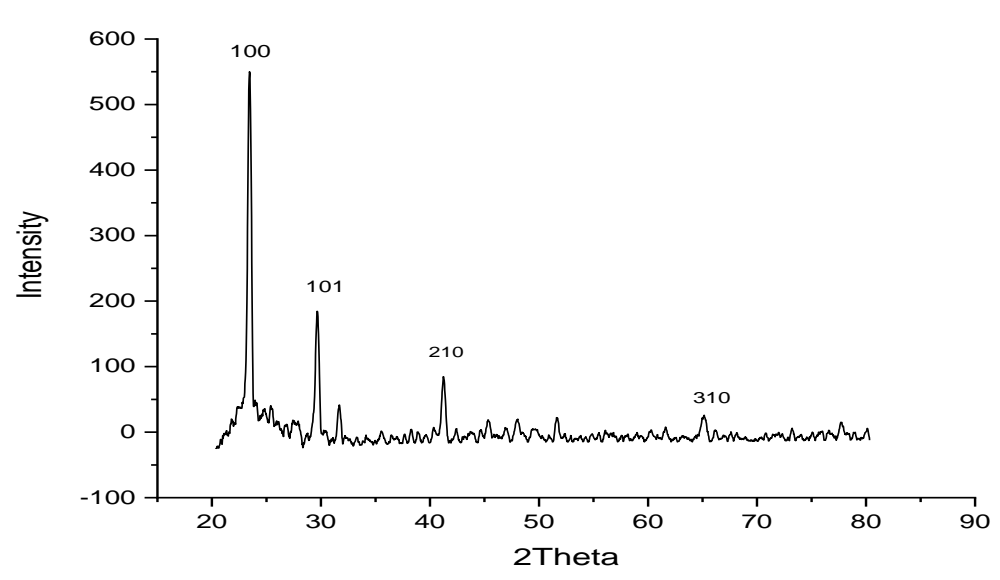

Figure (6) XRD Pattern of SeNPs.

\section{Transmission Electron Microscopy (TEM)}

TEM was carried out to observe the particle size and morphology of the synthesized Se-TPGS samples with different $500 \mathrm{~nm}$ scale explained in Figure (7). The average particle size observed was 66.23. The particles were the spherical shape and they have uniform size distribution.

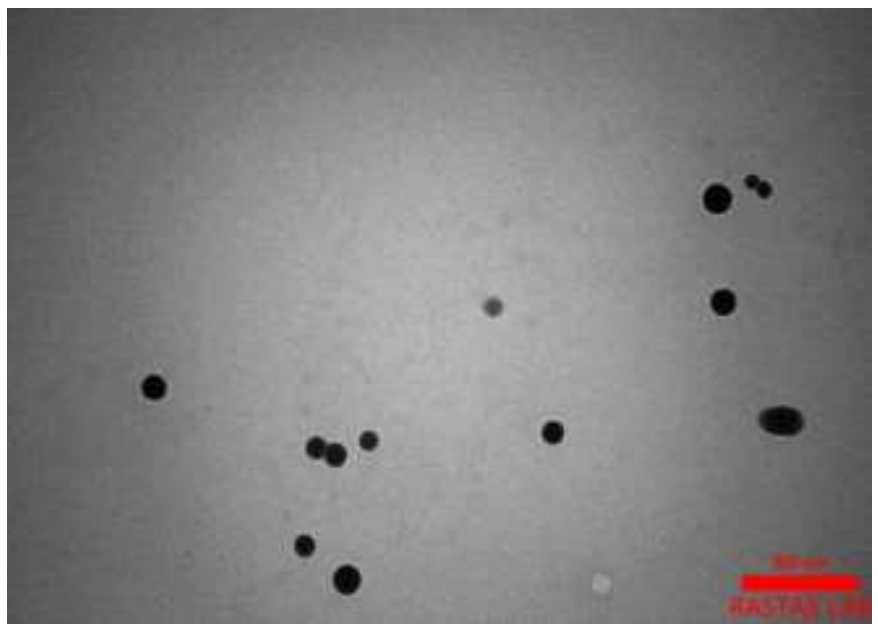

Figure (7) TEM images for Se-TPGS spherical nanoparticles with $500 \mathrm{~nm}$ scale.

\section{Field Emission Scanning Electron Microscopy}

The size average and form of nanoparticles in the test sample may be determined using FESEM imaging, which is an analytical method. Figure (8) shows a typical surface of prepared SeNPs from sodium selenite using ascorbic acid reduction, the 
FESEM picture revealed a spherical shape of SeNPs that formed with diameter ranges from $(56.61,63.87$ and 69.76$) \mathrm{nm}$.

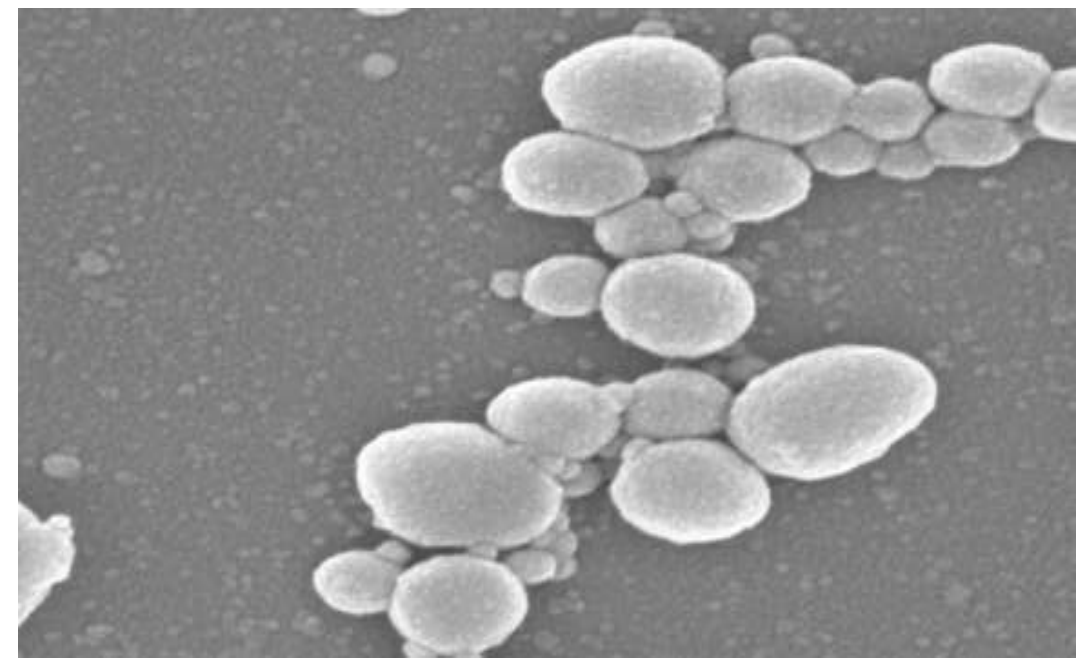

Figure (8) The FESEM image of spherical selenium nanoparticles.

\section{Evaluation of Antioxidant Potential In vitro}

The antioxidant activity of Se-TPGS compound was investigated by using DPPH experimental assay. The DPPH radical-scavenging (\%) activities are shown in exhibited a strong antioxidant activity Figure (9); the strong activity of the SeTPGS attributed to the synergic effect of both antioxidant activity for selenium and tocopherol compound primary components to scavenge DPPH free radicals. Nano antioxidants, principally that developed from materials that possess biological antioxidant potentials such as selenium or vitamins mainly vitamin $\mathrm{E}$ in their composition, are evolving new strategy for antioxidant therapies to treat and/or prevent disorders that involving oxidative stress. NPs due to their size and high surface area show robust interactions with molecules in biological systems so providing more effective against free radical induced damage than trivial molecule antioxidants. This effort describes a simplistic strategy for the synthesis of SeNPs [37]. Engineered nanoparticles have recently proposed as a unique technique for developing novel antioxidants with improved properties. The 
convert antioxidant element as Se to their nanoform then functionalized with natural antioxidants or antioxidant enzymes, in which nanoparticles serve as the carrier or antioxidant delivery vehicle, have been found to be effective in increasing antioxidant activity and providing targeted delivery of antioxidants that have poor permeation across cell membranes and cell internalization [38].

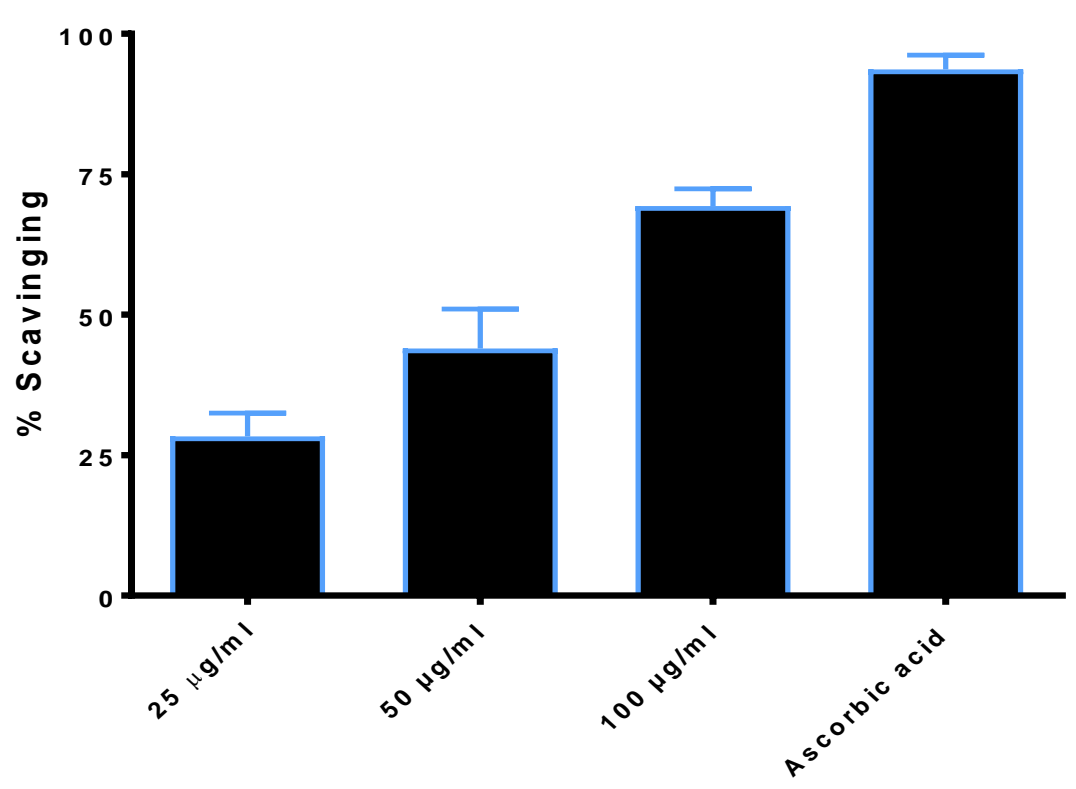

Figure (9) Antioxidant activity of Se-TPGS using DPPH assay.

\section{In vitro cytotoxicity}

In vitro cytotoxicity of Se-TPGS was evaluated by using MTT method at six concentrations $(6.25,12.5,25,50,100$ and 200) $\mu \mathrm{g} / \mathrm{ml}$ on both cancerous (MCF-7) as well as non-cancerous (HBL-100) cell lines. Several studies have investigated the effect of different selenium formulation and various tocopherol composites as a treatment for cancers. In vitro model methods (cell lines) and in vivo model for animals or human subjects have been investigate their anti-cancer activity through its apoptotic and anti-proliferative effects. The cytotoxic effect of Se-TPGS against cancer cells was studied. The antitumor activity of the Se-TPGS was tested by studying their ability to inhibit the proliferation of cancer cells. The 
results suggest the ability of Se-TPGS to suppress the growth of cell lines and this effect is concentration dependent manner. The results showed highly significant cytotoxic activity of Se-TPGS NPs against the human cancer cell lines as showed in Figure (10) with $\mathrm{IC}_{50}$ value for Se-TPGS NPs $36.26 \mu \mathrm{g} / \mathrm{ml}$ with slight effect against normal HBL-100 cell line Figure (11) the effect of different selenium species particularly SeNPs against cancerous cells mentioned at many in vitro and in vivo studies [39] and [24]. Selenium can exert pharmacological effect by inducing apoptosis in cancer cell in the absence of substantial side effects on normal cells, this anticancer effect is depended on various factors such as oxidation state, organic or inorganic nature of selenium compounds and the concentration remarkably doses at nearby to the Se toxic level [24]. On the other side Se compounds sensitize cancer cells by combining with standard radiotherapy or chemotherapy to improvement their efficiency and may act as a palliative agent [40]. GayaBover, evaluate antioxidant enzyme levels of superoxide dismutase, catalase, glutathione peroxidase and glutathione reductase enzymes both in cancer and noncancerous adjacent tissues from colorectal cancer patients, non-cancerous adjacent tissue appeared to have high levels of antioxidant enzymes compared to cancerous tissue [41]. For this reason, it can be interpret the effective of selenium species against cancer cells rather than normal cells (the incorporation of selenium with seleno-enzymes lead to increase activity of these enzymes then increase of antioxidant potential in normal cells). Cancer cells have a limited reserve capacity, resulting in an enhanced vulnerability of some cancer cells to reactive oxygen species (ROS), due to cancer cells constant greater synthesis of ROS and an activated antioxidant defense to counterbalance the increased basal ROS production. As a result, oxidative stress has been identified as a tumor-specific target for rational anticancer drug development. Due to their promising 
chemotherapeutic potential, selenium compounds have gotten a lot of interest among redox modifying chemicals [42]. Since nineties of the last century, researchers start study anticancer effects of vitamin E, several clinical trials conducted using $\alpha$-tocopherol as a major isoform of vitamin $\mathrm{E}$, to estimate its antineoplastic properties, based on the postulation that there is extreme production of oxidative stress substances in state of cancers. This anticancer effects of vitamin $\mathrm{E}$ has been recognized mainly to its anti-proliferative, antioxidant, anti-angiogenic and anti-inflammatory effects [25].

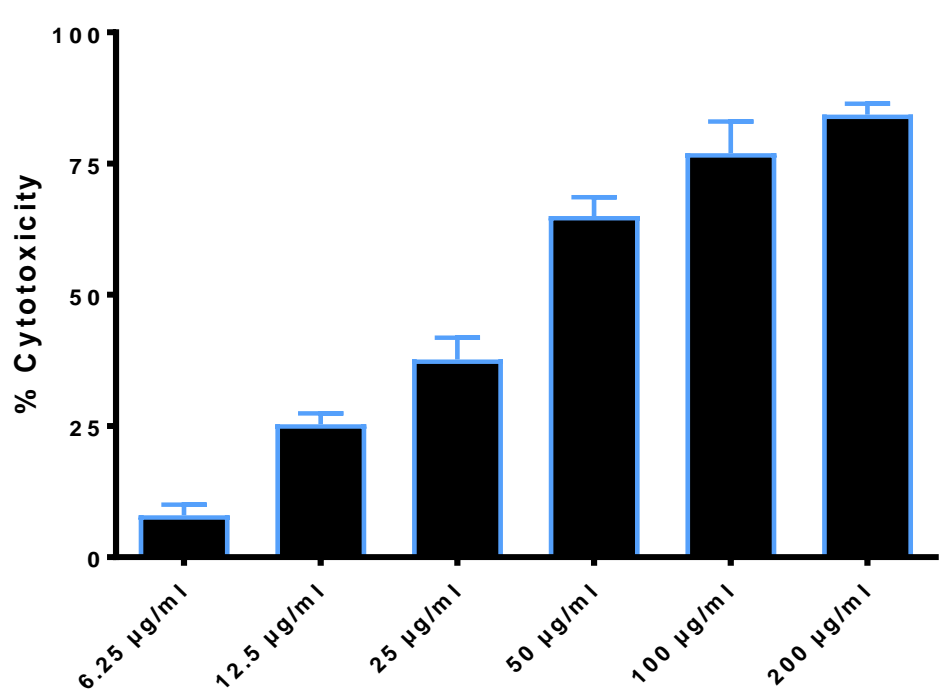

Figure (10) Cell viability MTT assay results for Se-TPGS against MCF-7 cell line (values are expressed as the mean \pm SD of triplicate measurements). 


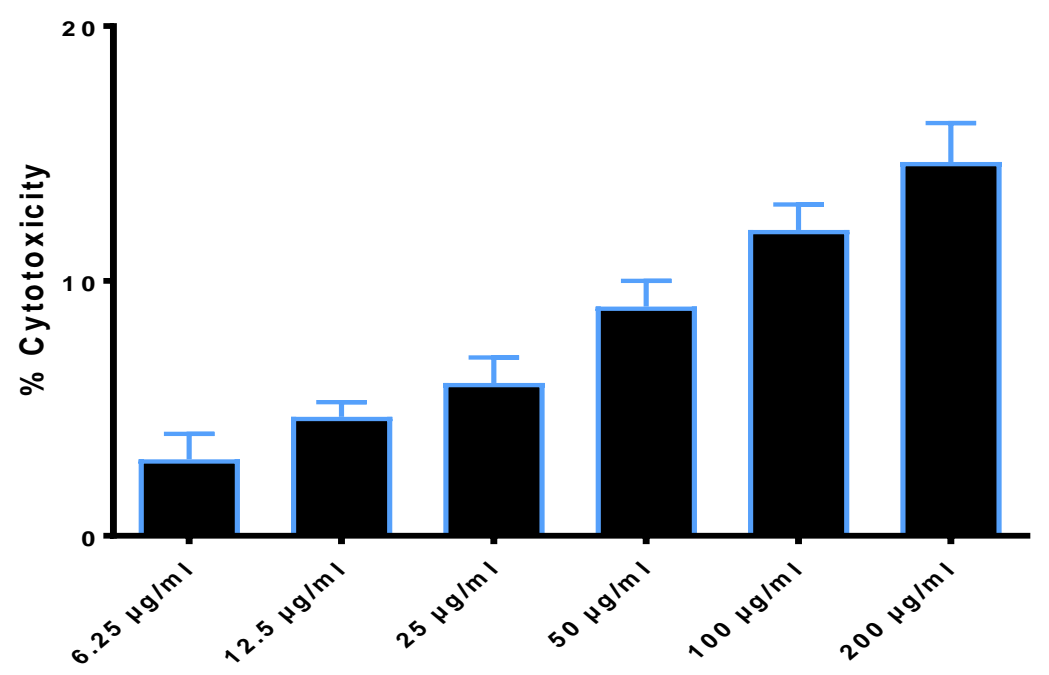

Figure (11) Cytotoxic effect of Se-TPGS in HBL cells.

\section{Cells Morphological Analysis}

When the cells visualized under inverted microscope, the both untreated cells have a standard morphology, attached to the surface and reached approximately 95-100\% confluence Figure (12A) and (13A). The morphological variations for treated MCF-7 cells are observed Figure (12B), such as losing of cell attachment, round and swelled cells. The cells tolerate growth inhibition because of which the cell density decreased and many cells appeared to be floating in the culture medium, while the HBL-100 show no change in their morphology, not floating and reached for confluence Figure (13B).

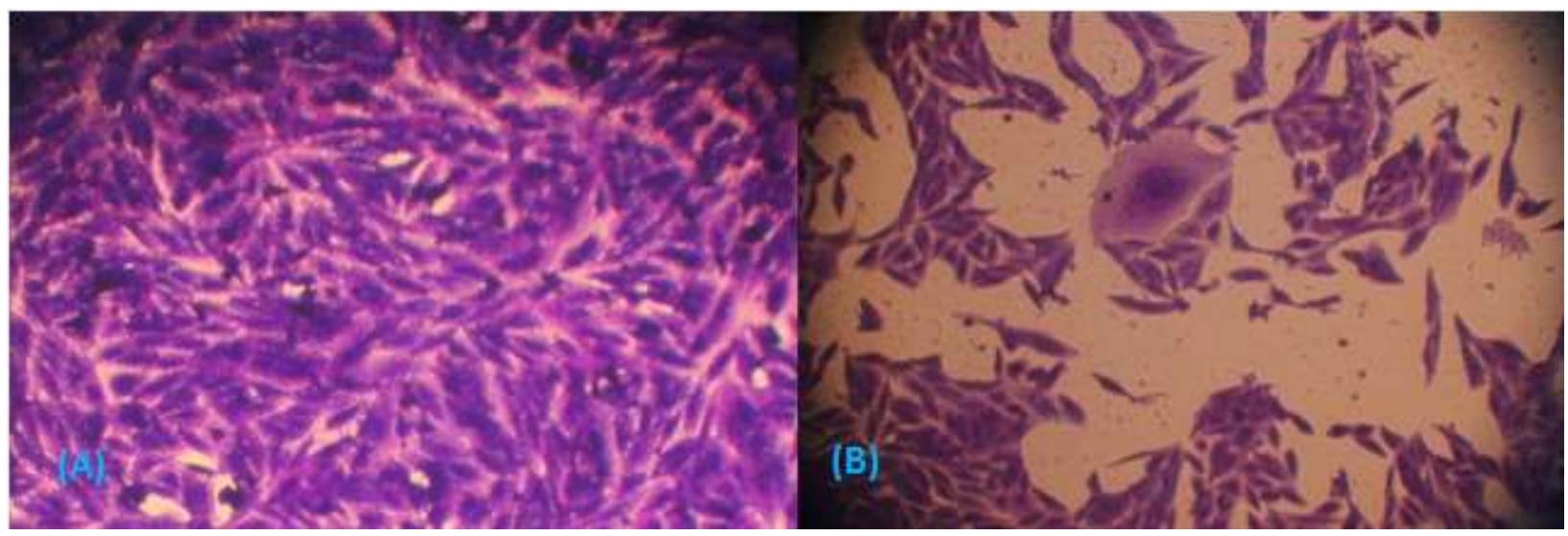

Figure (12) Morphological changes in MCF-7 cells, (A) Control un-treated MCF-7 cells, (B) after treated with Se-TPGS NPs. 


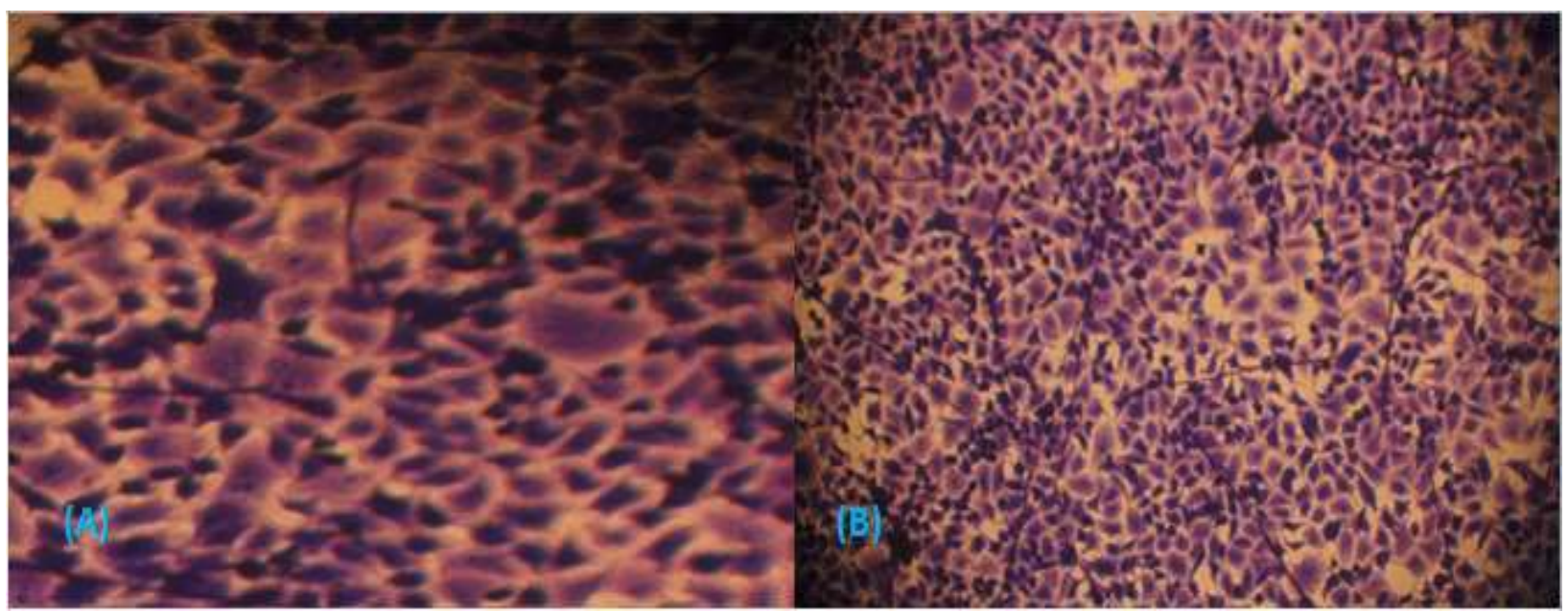

Figure (13) Morphological changes in HBL-100 cells, (A) Control un-treated HBL-100 cells, (B) cells after treated with Se-TPGS NPs.

\section{Acridine Orange-Ethidium Bromide Apoptosis Assay}

Acridine orange and ethidium bromide are two stains used as a method to examination the existence of apoptosis process that induced in MCF-7 cell line when exposed them to synthesized Se-TPGS NPs, Acridine orange a fluorescent cationic dye, pervade and permeable membrane of all cells types and bind to nucleic acid making the nuclei appear under florescent light microscope as a green color. Ethidium bromide is only taken up by cells when cytoplasmic membrane integrity is damaged, and bind to nucleic acid then stains the nuclei with orange color. Analysis of the $\mathrm{AO} / \mathrm{EB}$ staining demonstrated that the synthetic nano formulation induced apoptosis process in MCF-7 cells Figures (14B), with untreated cells as shown in Figure (14A), when compared with the live control cells were stained green and the apoptotic cells had orange spots in their nuclei. The appearance of chromatin condensation and nuclear fragmentation are evident in Figure (14). 


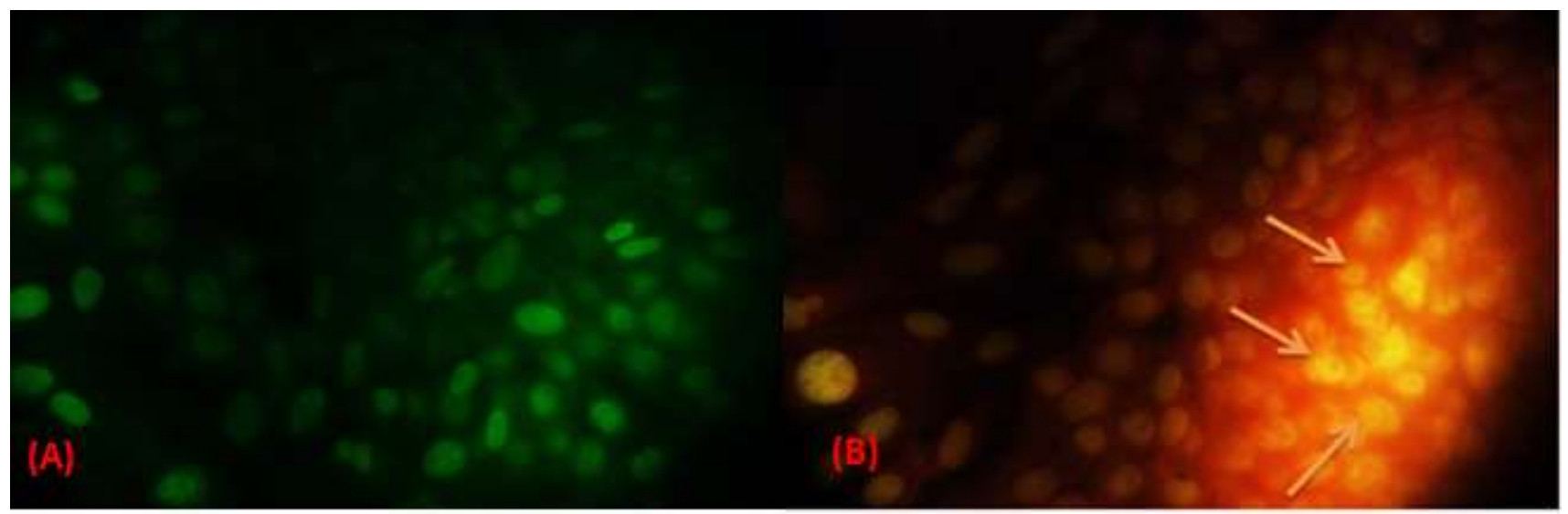

Figure (14) $\mathrm{AO} / \mathrm{EtBr}$ staining of $\mathrm{MCF}-7$ cells treated with $\mathrm{IC}_{50}$ of each formula for 24 hrs. (A) Untreated, (B) Se-TPGS.

\section{Hemolytic activity on red blood cells}

Despite the fact that most synthesized nanoparticles that supposed used in medical field will come into contact with blood at some point throughout their journey through the body, the interactions between these nanoparticles and blood cells are still poorly understood, and the importance of assessing nanoparticle hemocompatibility is severely underestimated [43]. Anemia and bacterial infection are a major side effects of anticancer chemotherapeutic drug due to reduction number of blood cells erythrocytes and leukocytes respectively [44]. So it is very essential to investigate influence of synthesized selenium nanoparticles Se-TPGS toward human erythrocytes.

Hemolysis studies were carried out on synthesized Se-TPGS NPs for the blood samples and examined erythrocytes visually and by using fluorescent microscope Figure (15B), when compare with untreated erythrocytes as control Figure (15A) that observed no hemolysis erythrocytes cells without any destruction or disruption of RBCs membranes when investigate by fluorescent microscope.

The using SeNPs are nontoxic when given orally for breast-feeding rats for three weeks, does not adversely influence to hematological and biochemical parameters. 
Contrasts the using of selenium ions as a (sodium selenite) that administrated in the similar conditions resulted in obvious damage to the mammary glands, with liver, kidney inflammations and deviated in blood parameters when comparing with control [45].

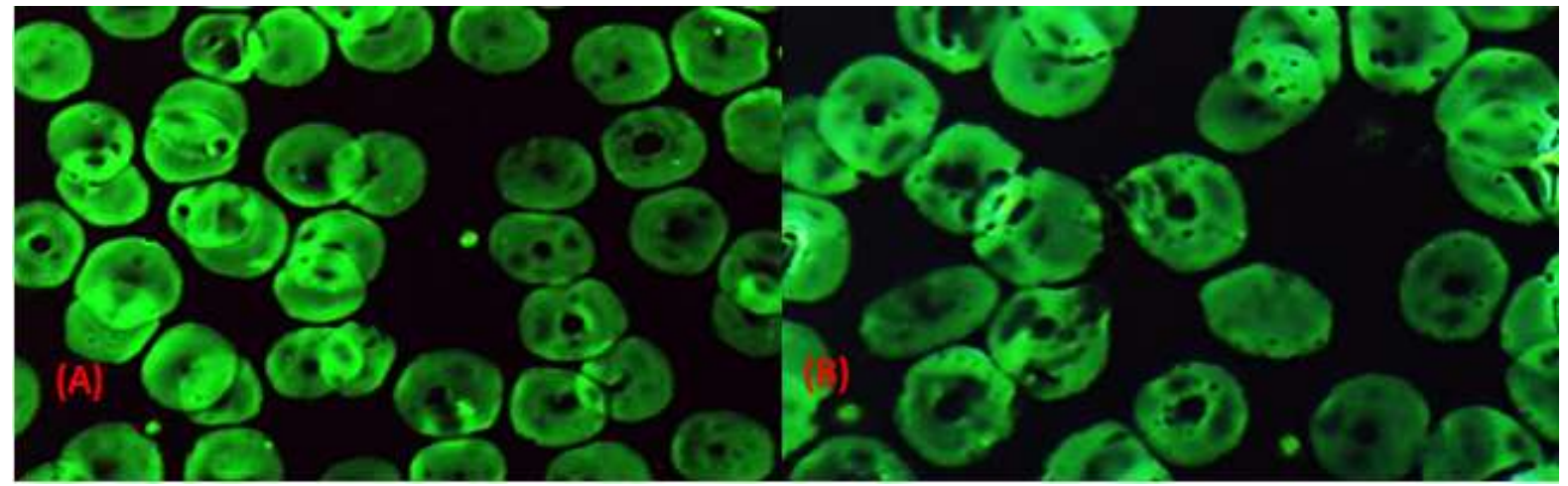

Figure (15) Hemolysis assay of red blood cells after incubation with (A) normal saline (control RBC). (B) with Se-TPGS NPs.

\section{Conclusion:}

Selenium nanoparticles are promising and attractive nano-platforms because robust biological selenium incorporation with body seleno-enzymes, this combination process (between selenium and seleno-enzymes) prompting activity of these enzymes in normal cells. selenium nanoparticles ability to surface coated (during synthesis process) by different protecting organic molecules with high capacity, especially for those have biological activity. Moreover these platforms foreseen to revolution in healthiness care by opening immense gate that providing novel approaches for combat cancer disease through three strategies including prevention, diagnosis and treatment.

\section{References :}


[1] Radomska, D., Czarnomysy, R., Radomski, D. and Bielawski, K., 2021. Selenium Compounds as Novel Potential Anticancer Agents. International Journal of Molecular Sciences, 22(3), p.1009.

[2] Hariharan, S. and Dharmaraj, S., 2020. Selenium and selenoproteins: it's role in regulation of inflammation. Inflammopharmacology, pp.1-29.

[3] Prasad, A.S., 2020. Clinical and immunological effects and biomarkers of zinc deficiency. In Essential and Toxic Trace Elements and Vitamins in Human Health (pp. 3-30). Academic Press.

[4] Majeed, M., Nagabhushanam, K., Gowda, S. and Mundkur, L., (2020) An exploratory study of selenium status in healthy individuals and in patients with COVID-19 in a south Indian population: The case for adequate selenium status. Nutrition, 82, p.111053.

[5] Zoidis, E., Seremelis, I., Kontopoulos, N. and Danezis, G.P., 2018. Selenium-dependent antioxidant enzymes: Actions and properties of selenoproteins. Antioxidants, 7(5), p.66.

[6] Avery, J.C. and Hoffmann, P.R., 2018. Selenium, selenoproteins, and immunity. Nutrients, 10(9), p.1203.

[7] Zhang, X., Liu, C., Guo, J. and Song, Y., 2016. Selenium status and cardiovascular diseases: meta-analysis of prospective observational studies and randomized controlled trials. European journal of clinical nutrition, 70(2), pp.162-169.

[8] Ikram, M., Javed, B., Raja, N.I. and Mashwani, Z.U.R., 2021. Biomedical potential of plant-based selenium nanoparticles: a comprehensive review on therapeutic and mechanistic aspects. International Journal of Nanomedicine, 16, p.249.

[9] Saeid, A. ed., 2017. Food Biofortification Technologies. CRC Press.

[10] Brousseau, P., Payette, Y., Tryphonas, H., Blakley, B., Boermans, H., Flipo, D., Fournier, M., Beaudet, M., Kouassi, E., Lapierre, P. and Voccia, I., 2021. Manual of immunological methods. CRC press.

[11] Sunil, D., Kamath, P.R. and Chandrashekhar, H.R., 2017. In vitro bioassay techniques for anticancer drug discovery and development. CRC Press. 
[12] Boroumand, S., Safari, M., Shaabani, E., Shirzad, M. and Faridi-Majidi, R., 2019. Selenium nanoparticles: synthesis, characterization and study of their cytotoxicity, antioxidant and antibacterial activity. Materials Research Express, 6(8), p.0850d8.

[13] Khashan, K. S., Sulaiman, G. M., Hussain, S. A., Marzoog, T. R., and Jabir, M. S. (2020). Synthesis, characterization and evaluation of anti-bacterial, anti-parasitic and anti-cancer activities of aluminum-doped zinc oxide nanoparticles. Journal of Inorganic and Organometallic Polymers and Materials, 1-17.

[14] Ali, Z., Jabir, M., \& Al-Shammari, A. (2019). Gold nanoparticles inhibiting proliferation of Human breast cancer cell line. Research Journal of Biotechnology, 14, 79-82.

[15] Al-Ziaydi, A. G., Al-Shammari, A. M., Hamzah, M. I., Kadhim, H. S., \& Jabir, M. S. (2020). Newcastle disease virus suppress glycolysis pathway and induce breast cancer cells death. Virus Disease, 1-8.

[16] Khashan, K. S., Jabir, M. S., \& Abdulameer, F. A. (2019). Carbon Nanoparticles prepared by laser ablation in liquid environment. Surface Review and Letters, 26(10), 1950078.

[17] Jabir, M. S., Taha, A. A., Sahib, U. I., Taqi, Z. J., Al-Shammari, A. M., \& Salman, A. S. (2019). Novel of nano delivery system for Linalool loaded on gold nanoparticles conjugated with CALNN peptide for application in drug uptake and induction of cell death on breast cancer cell line. Materials Science and Engineering: C, 94, 949-964.

[18] Mees, D.R., Pysto, W. and Tarcha, P.J., 1995. Formation of selenium colloids using sodium ascorbate as the reducing agent. Journal of colloid and interface science, 170(1), pp.254-260.

[19] Zhang, J., Teng, Z., Yuan, Y., Zeng, Q.Z., Lou, Z., Lee, S.H. and Wang, Q., 2017. Development, physicochemical characterization and cytotoxicity of selenium nanoparticles stabilized by beta-lactoglobulin. International journal of biological macromolecules, 107, pp.1406-1413.

[20] Mishra, R.R., Prajapati, S., Das, J., Dangar, T.K., Das, N. and Thatoi, H., 2011. Reduction of selenite to red elemental selenium by moderately halotolerant Bacillus 
megaterium strains isolated from Bhitarkanika mangrove soil and characterization of reduced product. Chemosphere, 84(9), pp.1231-1237.

[21] Singh, M.R., Singh, D., Kanwar, J. and Chauhan, N.S. eds., 2020. Advances and Avenues in the Development of Novel Carriers for Bioactives and Biological Agents. Academic Press.

[22] Mates, I., Antoniac, I., Laslo, V., Vicas, S., Brocks, M., Fritea, L., Milea, C., Mohan, A. and Cavalu, S., 2019. Selenium nanoparticles: Production, characterization and possible applications in biomedicine and food science. Sci. Bull. B Chem. Mater. Sci. UPB, 81, pp.205-216.

[23] Geoffrion, L.D., Hesabizadeh, T., Medina-Cruz, D., Kusper, M., Taylor, P., Vernet-Crua, A., Chen, J., Ajo, A., Webster, T.J. and Guisbiers, G., 2020. Naked selenium nanoparticles for antibacterial and anticancer treatments. ACS omega, 5(6), pp.2660-2669.

[24] Khurana, A., Tekula, S., Saifi, M.A., Venkatesh, P. and Godugu, C., 2019. Therapeutic applications of selenium nanoparticles. Biomedicine and Pharmacotherapy, 111, pp.802-812.

[25] Abraham, A., Kattoor, A.J., Saldeen, T. and Mehta, J.L., 2019. Vitamin E and its anticancer effects. Critical reviews in food science and nutrition, 59(17), pp.28312838 .

[26] Dawood, M.A., Zommara, M., Eweedah, N.M. and Helal, A.I., 2019. Synergistic effects of selenium nanoparticles and vitamin $\mathrm{E}$ on growth, immune-related gene expression, and regulation of antioxidant status of Nile tilapia (Oreochromis niloticus). Biological trace element research, pp.1-12.

[27] Naderi, M., Keyvanshokooh, S., Salati, A.P. and Ghaedi, A., 2017. Effects of dietary vitamin $\mathrm{E}$ and selenium nanoparticles supplementation on acute stress responses in rainbow trout (Oncorhynchus mykiss) previously subjected to chronic stress. Aquaculture, 473, pp.215-222.

[28] Oliveira, J.P., Prado, A.R., Keijok, W.J., Ribeiro, M.R., Pontes, M.J., Nogueira, B.V. and Guimarães, M.C., 2020. A helpful method for controlled synthesis of 
monodisperse gold nanoparticles through response surface modeling. Arabian Journal of Chemistry, 13(1), pp.216-226.

[29] Kokila, K., Elavarasan, N. and Sujatha, V., 2017. Diospyros montana leaf extract-mediated synthesis of selenium nanoparticles and their biological applications. New Journal of Chemistry, 41(15), pp.7481-7490.

[30] Al-Kurdy, M.J., 2020. Synthesis and Characterization of Black Currant Selenium Nanoparticles (Part I). The Iraqi Journal of Veterinary Medicine, 44(2), pp.25-34.

[31] Khiralla, G.M. and El-Deeb, B.A., 2015. Antimicrobial and antibiofilm effects of selenium nanoparticles on some foodborne pathogens. LWT-Food Science and Technology, 63(2), pp.1001-1007.

[32] Gangadoo, S., Stanley, D., Hughes, R.J., Moore, R.J. and Chapman, J., 2017. The synthesis and characterisation of highly stable and reproducible selenium nanoparticles. Inorganic and Nano-Metal Chemistry, 47(11), pp.1568-1576.

[33] El-Deeb, B., Al-Talhi, A., Mostafa, N. and Abou-assy, R., 2018. Biological synthesis and structural characterization of selenium nanoparticles and assessment of their antimicrobial properties. American Scientific Research Journal for Engineering, Technology, and Sciences, 45(1), pp.135-170.

[34] Nayem, S. M., Sultana, N., Haque, M., Miah, B., Hasan, M., Islam, T., and Ahammad, A. J. "Green synthesis of gold and silver nanoparticles by using amorphophallus paeoniifolius tuber extract and evaluation of their antibacterial activity". Molecules, 25(20), 4773.2020) ).

[35] Sarkar, J., Dey, P., Saha, S. and Acharya, K., 2011. Mycosynthesis of selenium nanoparticles. Micro \& nano letters, 6(8), pp.599-602.

[36] Filipović, N., Veselinović, L., Ražić, S., Jeremić, S., Filipič, M., Žegura, B., Tomić, S., Čolić, M. and Stevanović, M., 2019. Poly ( $\varepsilon$-caprolactone) microspheres for prolonged release of selenium nanoparticles. Materials Science and Engineering: C, 96, pp.776-789.

[37] Zhang, W., Zhang, J., Ding, D., Zhang, L., Muehlmann, L.A., Deng, S.E., Wang, X., Li, W. and Zhang, W., 2018. Synthesis and antioxidant properties of Lycium 
barbarum polysaccharides capped selenium nanoparticles using tea extract. Artificial cells, nanomedicine, and biotechnology, 46(7), pp.1463-1470.

[38] Khalil, I., Yehye, W.A., Etxeberria, A.E., Alhadi, A.A., Dezfooli, S.M., Julkapli, N.B.M., Basirun, W.J. and Seyfoddin, A., 2020. Nanoantioxidants: Recent trends in antioxidant delivery applications. Antioxidants, 9(1), p.24.

[39] Kuršvietienè, L., Mongirdienè, A., Bernatonienè, J., Šulinskienè, J. and Stanevičienè, I., 2020. Selenium anticancer properties and impact on cellular redox status. Antioxidants, 9(1), p.80.

[40] Radomska, D., Czarnomysy, R., Radomski, D. and Bielawski, K., 2021. Selenium Compounds as Novel Potential Anticancer Agents. International Journal of Molecular Sciences, 22(3), p.1009.

[41] Gaya-Bover, A., Hernández-López, R., Alorda-Clara, M., de la Rosa, J.M.I., Falcó, E., Fernández, T., Company, M.M., Torrens-Mas, M., Roca, P., Oliver, J. and Sastre-Serra, J., 2020. Antioxidant enzymes change in different non-metastatic stages in tumoral and peritumoral tissues of colorectal cancer. The international journal of biochemistry \& cell biology, 120, p.105698.

[42] Fernandes, A.P. and Gandin, V., 2015. Selenium compounds as therapeutic agents in cancer. Biochimica et Biophysica Acta (BBA)-General Subjects, 1850(8), pp.1642-1660.

[43] de la Harpe, K.M., Kondiah, P.P., Choonara, Y.E., Marimuthu, T., du Toit, L.C. and Pillay, V., 2019. The hemocompatibility of nanoparticles: a review of cellnanoparticle interactions and hemostasis. Cells, 8(10), p.1209.

[44] Mitra, S. and Dash, R., 2018. Natural products for the management and prevention of breast cancer. Evidence-Based Complementary and Alternative Medicine, 2018.

[45] Chandramohan, S., Naveenkumar, S., Kaviyarasu, K., Lavakumar, V., Sowmya, C., Santhanakumar, M. and Muthukumaran, A., 2021. Bio-distribution of selenium nanoparticles (SeNPs) to the Wistar rats and its breastfed offspring. Journal of Drug Delivery Science and Technology, 61, p.102299. 